\title{
EL REINO DE ARAGÓN EN LA ÉPOCA DE JAIME II (1291-1327)
}

\author{
Esteban SARASA SÁNCHEZ \\ Universidad de Zaragoza
}

La figura y obra de Jaime II ha merecido desde siempre una especial dedicación de los estudiosos que han tratado el tema desde una perspectiva general de la Corona o desde la particular de su entorno familiar ${ }^{\dagger}$. A demás, cuestiones como las relacionadas con la expansión por oriente de los almogávares ${ }^{2}$ o la intervención en Cerdeña ${ }^{3}$ han merecido igualmente la atención en diversas ocasiones.

Sin embargo, faltan estudios adecuados sobre la actuación del monarca en cada uno de sus estados o acerca de la situación de los mismos en su época; además de echarse en falta igualmente un balance global del reinado que sólo la conjunción de los diferentes y heterogéneos trabajos dedicados a esos años permite adelantar como punto de partida para valorar una actuación común o una intervención concreta ${ }^{4}$.

1 MUÑOZ POMER, M.R. y PINILLA PÉREZ DE TUDELA, R.: «Studi e ricerche dedicati a Giacomo II d'Aragona in Spagna (1850-1995)", en Medioevo. Saggi e rassegne 20, Cagliari 1995, pp. 399-460. Todo el volumen está dedicado en varios artículos de diversos autores a la Corona d'Aragona $e$ Mediterraneo. Strategie d'expansione, migrazioni e commerci nell'età di Giacomo II.

2 SARASA, E.: “Los almogávares. Del caudillaje a la república militar», en Historia 16, num. 233, septiembre 1995, pp. 54-58. Aunque, entre otra bibliografía cabe señalar el libro clásico de Ferrán SOLDEVILA, Els almogàvers, Episodis de la Historia 299, Dalmau editor, Barcelona 1952 (1994); así como algunos trabajos de $\mathrm{M}^{\mathrm{a}}$ Teresa FERRER.

3 XIV Congresso di Storia della Corona d'Aragona, varios volúmenes, Sassari 1996.

4 MARTÍNEZ FERRANDO, J.E.: Jaume // (en Els descendents de Pere el Gran, Història de Catalunya. Biografies Catalanes, vol. 6), Vicens-Vives, Barcelona 1954 (varias reediciones), pp. 59. 166. Este autor es el primero de los grandes estudiosos del rey y su obra. Entre sus múltiples publicaciones acerca del mismo sobresale por su originalidad, que no se encuentra en otros estudios similares, su libro sobre Jaime // de Aragón. Su vida familiar, C.S.I.C., Barcelona 1948. 
En el caso del reino de Aragón, el reinado de Jaime ll es de los más descuidados; sin embargo remitimos a tres aportaciones de diferente carácter y condición realizadas en los últimos veinte años: los trabajos de Luis González Antón al respecto ${ }^{5}$, las actas del XIV Congreso de la Corona de Aragón celebrado en Cerdeña en 1990 y las páginas que de diversos autores se pueden entresacar sobre la cuestión ${ }^{6}$, y los contenidos de la XXI Semana de Estudios Medievales de Estella del año 1994 dedicada a los umbrales de las crisis entre 1250 y $1350^{7}$. Con lo que ya podemos disponer de una buena base para historiar, analizar y recomponer el reinado de Jaime II en Aragón; sobre todo a partir de 1300, en la segunda parte del mismo, porque la situación cambió con el siglo que dobló este monarca y descompensó la inicial armonía de los dominios del rey, peninsulares e insulares ${ }^{8}$.

Pero existen algunos motivos que acaso justifiquen la escasa dedicación de la historiografía aragonesa, salvo en los casos señalados ${ }^{9}$, a la época de este monarca; tales como la abundancia documental de la Cancillería frente a la escasa documentación local, particular o reinal. Es decir, la necesidad de acudir al Archivo de la Corona de Aragón en Barcelona para tejer un primer entramado que permita después focalizar el interés en una cuestión particular, local o coyuntural ${ }^{10}$. O también, por qué no, el mero hecho, aunque no desdeñable, de coincidir esos años, a caballo del 1300 , con el inicio del atraso económico y político de Aragón, el reino interior de la Corona ${ }^{11}$. Y ello a pesar de que Jaime II sobresale, en principio, como pacificador de una situación heredada de sus predecesores tras la guerra civil de la Unión, la división de los aragoneses y el desentendimiento de las empresas mediterráneas; porque, Jaime II aún logrará reconducir en parte la deteriorada situación y concitar el interés por la empre-

5 Las Uniones aragonesas y las Cortes del Reino (1283-1301), 2 vols. C.E.M.A., Zaragoza 1975; «Las Cortes aragonesas en el reinado de Jaime II», en Anuario de Historia del Derecho Español 1977, pp. 523-682; y "Jaime Il y la afirmación del poder monárquico en Aragón», en A la profesora emérita Maria Luisa Ledesma Rubio en homenaje académico (Aragón en la Edad Media X-XI) Universidad de Zaragoza 1993, pp. 385-405.

6 Ver nota 3.

7 Europa en los umbrales de la crisis (1250-1350), VV.AA., Gobierno de Navarra, Pamplona 1995.

8 Como a raíz del tratado de Torrellas en 1304, o sentencia arbitrada entre Jaime II de Aragón y Fernando IV de Castilla, por intervención del rey de Portugal, el infante don Juan (hijo de Alfonso X el Sabio) y el arzobispo de Zaragoza; sobre la influencia en Alicante y la frontera en Murcia de las dos Coronas litigantes; renunciando el aragonés a Murcia pero incluyendo en sus dominios el bajo Segura: desde Alicante hasta Orihuela; con una reafirmación posterior en el tratado de Elche de 1305. Con ello, el rey pudo iniciar su política mediterránea que le llevaría a Cerdeña.

9 Notas 3 y 5 . A partir de ahora fijaremos sobre todo la bibliografía sobre Aragón, pues el libro que contiene esta aportación, ya se refiere en sus páginas a la más completa.

10 La documentación del reinado de Jaime Il es proporcionalmente a los años del mismo muy superior a la de cualquier otro reinado. Sólo en Registros de Cancillería existen catalogados en dicho Archivo 259 registros, sin contar los de las diversas lugartenencias.

11 SARASA, E. y ORCÁSTEGUI, C.: El rechazo de la aventura mediterránea y la manifestación de las contradicciones internas: la consolidación del reino y los comienzos de la crisis (1276-1336), en Historia de Aragón 6, Guara Editorial, Zaragoza 1985, pp. 11-46. 
sa de Cerdeña, en la cual los aragoneses participarán con medios e intervenciones personales ${ }^{12}$.

Es decir, si a Jaime II se le pueden adjudicar los méritos propios de un gran diplomático, de una política expansionista brillante y de una voluntad pacificadora ${ }^{13}$, sin embargo su trayectoria comprende éxitos y fracasos, luces y sombras, que combinan: las decepciones de Almeria o de las Cruzadas ${ }^{14}$; el tratado de Monteagudo (1291) ${ }^{15}$, o la incorporación de Alicante y Murcia a la Corona (1296) ${ }^{16}$.

En este contexto general, Aragón entró en la nueva época con una gran crisis política arrastrada desde $1283^{17}$ y que mostraba las contradicciones internas del sistema ${ }^{18} \mathrm{y}$ el endurecimiento de las relaciones del reino con la monarquía ${ }^{19}$, las consecuencias del final de la "reconquista natural»" ${ }^{20}$, la reconducción institucional ${ }^{21}$, la sensación de abandono de los regnícolas ${ }^{22}$ y la parálisis del crecimiento económica y el inicio de la recesión ${ }^{23}$.

La contestación, la desobediencia civil, las alteraciones y el desentendimiento general fue por entonces la reacción de Aragón ante un experimento inacabado e interrumpido que conllevó al fracaso de un proyecto aragonés, diluido en la concentra-

12 ORCÁSTEGUI, C.: «Contribución económica de los aragoneses a las empresas de Cerdeña (siglo XIV)", en XIV Congresso di Storia della Corona d'Aragona, obra citada, vol. 3, pp. 659-666; y SARASA, E.: «Repercusiones político-sociales en el reino de Aragón de la intervención de la Corona en Cerdeña (siglo XIV)», ibidem, pp. 723-729.

13 "Jaime II y la pacificación del reino", en Historia de Aragón 6 (nota 11), pp. 29-30.

14 MARTÍNEZ FERRANDO, J.E.: «Guerres amb els musulmans de Granada, expedició a Almería» (Jaume II, obra citada, pp. 115-119). Respecto a sus veleidades de cruzado, este autor dice al respecto: «Alguna vegada Jaume II, potser amb excés d'ingenuitat, va intentar de convertir al cristianisme algun dels sobirans mahometans. Tampoc el proselitisme directe que va dur a terme Ramon Llull en alguns viatges que emprengué entre 1292 i 1315 a Tunis i Bugia no tingué cap resultat positiu» (p. 130).

15 Por el tratado de Monteagudo de 1291 se proponía el matrimonio del rey con la hija de Sancho IV de Castilla, buscando el apoyo castellano (matrimonio que no se efectuó); el compromiso de colaborar con Castilla en la lucha contra el Islam benimerín dentro de la política sobre el Estrecho, la ayuda del castellano frente a Francia y un supuesto reparto del norte de Africa en caso de ocupación cristiana por parte de ambas Coronas hispanas. Sin embargo, fracasados los propósitos, el incumplimiento de lo acordado obligó a Jaime II a renunciar a Sicilia en el tratado de Anagni de 1295 y a la herencia de los Hohenstaufen.

16 DEL ESTAL, J.M.: Conquista y anexión de las tierras de Alicante, Elche, Orihuela y Guardamar al reino de Valencia por Jaime II (1296-1308), Valencia 1982; y El reino de Murcia bajo Aragón (12961305). Corpus documental, 2 vols. Alicante 1985 y 1990 respectivamente. Asi como de HINOJOSA MONTALVO, J.: “Anexión del Alicante meridional a la Corona de Aragón» (en Las tierras alicantinas en la Edad Media, Alicante 1995, pp. 30-33).

17 Ver nota 11.

18 Ibidem.

19 Ibidem.

20 Ibidem.

21 lbidem.

22 Ibidem.

23 Ibidem. 
ción del interés de la Corona sobre el Mediterráneo y Levante ${ }^{24}$. Teniendo como resultado la dislocación de intereses de los estados de la Corona y el refuerzo de las instituciones propias y diferenciadas ${ }^{25}$.

De ahí que, en el caso aragonés, la tensión desencadenada hasta entonces se contuvo y soterró en parte por la reconducción institucionap ${ }^{6}$, la superación de la división sociaf ${ }^{7}$ y el intento de reconstrucción económica ${ }^{28}$. Motivaciones que permitieron al rey pacificar el reino a la vez que aplicar medidas apenas contestadas, pero fortalecedoras del poder regio, tendentes a la recomposición del Patrimonio Rea ${ }^{9}$, la reorganización administrativa ${ }^{30}$, y la fiscalidad ${ }^{\beta 1}$; mientras que facilitó la adopción de soluciones tan dramáticas e impopulares en principio como la disolución de la Orden del Temple $e^{32}$, tan arraigada en Aragón, o la implicación aragonesa en la empresa de Cerdeña ${ }^{33}$. Todo lo cual se abordó sobre todo en la segunda parte del reinado de Jaime II, que para Aragón se puede empezar a considerar a partir de 1300, es decir los dos segundos tercios de su mandato ${ }^{34}$.

Esto significa que es a través de los cambios, comportamientos y operaciones reseñadas como se puede abordar, en principio, una valoración global de dicho reinado en Aragón; si bien teniendo en cuenta que pueden quedar otros aspectos complementarios que explican aún mejor el balance, al parecer más bien positivo que negativo, del mismo. La prueba es que, a pesar de las dificultades propias de un contexto internacional y ambiental desfavorable ${ }^{35}$, tras las graves alteraciones y disfunciones de los reinados de Pedro el Grande (1276-1285 $)^{36}$ y Alfonso el Liberal o el Franco $(1285-1291)^{37}$, el tiempo de Jaime II aparece como un paréntesis activo, dinámico y

24 XIV Congresso di Storia della Corona d'Aragona, obra citada.

25 Nota 11.

26 L. GONZÁLEZ ANTÓN, «Las Cortes aragonesas en el reinado de Jaime Il», obra citada.

27 «A pesar de todo, las condiciones fueron favorables a un largo periodo de tregua por parte de la Unión, bajo el ordenamiento de Jaime II..." (SARASA, E.: Sociedad y conflictos sociales en Aragón: siglos XIII-XV, Madrid 1981, p. 51).

28 De lo que las Cortes del periodo son testigo y demostración (GONZÁLEZ ANTÓN, L.: «Las Cortes aragonesas en el reinado de Jaime 1 "»).

29 SARASA, E.: "La incidencia del patrimonio real en el tejido social aragonés durante la Baja Edad Media» (en Col.loqui: Corona, municipio i fiscalitat a la Baixa Edat Mitjana, Institut d'Estudis llerdencs, en prensa).

30 SARASA, E. y ORCÁSTEGUI, C.: Historia de Aragón 6, obra citada.

31 SARASA, E.: obra citada en la nota 29.

32 SARASA, E.: "La supresión de la Orden del Temple en Aragón. Proceso y consecuencias» (en Congreso: Las Órdenes Militares en la Península Ibérica, Universidad de Castilla-La Mancha, en prensa).

33 Ver nota 12.

34 GONZÁLEZ ANTÓN, L.: «Las Cortes aragonesas en el reinado de Jaime II».

35 SARASA, E.: Sociedad y conflictos sociales en Aragón; siglos XIII-XV.

36 Ibidem.

37 Ibidem. 
socializador, para recaer después en las crisis propias, conjugadas ahora con las añadidas del siglo XIV, desde los comienzos de Pedro el Ceremonioso ${ }^{38}$.

El elevado número de convocatorias de Cortes para los aragoneses en estos años, ${ }^{39}$ el especial hincapié en dotar al reino de una infraestructura administrativa propia ${ }^{40} \mathrm{o}$ la regulación impositiva de algunas recaudaciones nacidas anteriormente con carácter extraordinario y que ahora se las reconvierte en periódicas ${ }^{41}$, manifiesta al menos que Jaime II, a pesar de sus implicaciones internacionales y peninsulares, y de sus intereses supraterritoriales, atajó la sensación de abandono y desencanto que los regnícolas habían achacado a sus predecesores ${ }^{42}$.

Por otro lado, acaso uno de los grandes logros del monarca fue para Aragón la incorporación de la sociedad aragonesa en su conjunto diferenciado a las estructuras del poder y del gobierno particular del reino; contando con oriundos del país para la ejecución de las misiones propias de la administración real en el mismo. Con lo que se superó la deuda pendiente en este caso por lo que se consideraba como injerencia extraña en los asuntos aragoneses y la falta de correspondencia al respecto ${ }^{43}$. Acaso porque Jaime II inició una política sostenida de gobernar distintamente para cada uno de sus estados ${ }^{44}$, sin menoscabo de una gobernabilidad general pero respetando en cada caso las instituciones propias y las necesidades territoriale ${ }^{45}$.

En efecto, Jaime II atendió en particular al reino de Aragón en un clima de convivencia, confianza y compromiso desconocido hasta entonces después de una segunda mitad del siglo XIII caracterizada por lo contrario y que había puesto en duda tanto el proyecto común de la Corona como la realización particular de Aragón ${ }^{46}$. Se saldaron agravios, se estrecharon diferencias y se articularon los procesos y mecanismos de participación y contribución en la responsabilidad colectiva ${ }^{47}$. Y todo ello sin los reproches que los aragoneses habían hecho a Pedro el Grande por sus actuaciones mediterráneas ${ }^{48}$.

En definitiva, los treinta y seis años de reinado de Jaime II en Aragón sirvieron sobretodo para reconducir una situación de extrema conflictividad social, de expectativas económicas en suspenso y de retraimiento estamental ${ }^{49}$, hacia la conjunción de

38 Ibidem.

39 GONZÁLEZ ANTÓN, L.: «Las Cortes aragonesas en el reinado de Jaime $\|$ ».

40 SARASA, E. y ORCÁSTEGUI, C.: Historia de Aragón 6, obra citada.

41 ORCÁSTEGUI, $C_{\text {.: }}$ «La reglamentación del monedaje en Aragón en los siglos XIII-XIV», en Aragón en la Edad Media V, Zaragoza 1983, pp. 113-121.

42 SARASA, E. y ORCÁSTEGUI, C.: Historia de Aragón 6, obra citada.

43 Ibidem.

44 Ibidem.

45 Ibidem.

46 Ibidem.

47 Ibidem.

48 SARASA, E.: El privilegio General de Aragón. La defensa de las libertades aragonesas en la Edad Media, Cortes de Aragón, Zaragoza 1984.

49 GONZÁLEZ ANTÓN, L.: obras citadas en la nota 5. 
intereses comunes canalizados por la monarquía a través de un esfuerzo de reinstitucionalización que sentó las bases definitivas de un sistema perdurable $e^{50}$.

El arranque de su actitud personal son las primeras Cortes del reinado, inmediatamente estrenado, en 1291, y en las que logra desmontar el movimiento unionista, aislar a la nobleza más contraria a su causa y ganarse a la nobleza inferior y a las universidades ${ }^{51}$.

En dicha asamblea se encontraron los dos propósitos que iban a dirigir la actuación real por un lado y las aspiraciones aragonesas por otro; es decir, la consolidación de la monarquía con la superación del predominio señorial y el protagonismo regular de los sectores no aristocráticos respectivamente ${ }^{52}$. Con lo cual se abrieron unas pautas responsables del resto del mandato en lo que concierne al ideario político del rey y al proyecto del reino ${ }^{53}$. y se afirmaron ambos propósitos en la asamblea de $1300^{54}$. en la que, entre otros logros, obtuvo el soberano un compromiso importante en el beneficio de la sal, que iba a introducir en las Cortes la vertiente económica y fiscal que hasta entonces no se había desarrollado ${ }^{55}$.

No por conocida la cuestión se puede eludir en este punto, el papel jugado por las Cortes a partir de 1300 y a lo largo de los veintisiete años restantes del monarca ${ }^{56}$, ya que fueron la plataforma en la que se vertieron y debatieron los intereses de gobernantes y gobernados a partir del momento de la incorporación de la Iglesia como estamento o «brazo» (el cuarto de Aragón) ${ }^{57}$ y tras el compromiso, incumplido pero presente, de la obligada regularidad en las convocatorias ${ }^{58}$, para las que la imagen de la inversión del deber de asistencia en derecho de presencia puede resultar meramente virtual pero asumible ${ }^{59}$.

Junto a ello, el requerimiento a la Justicia para resolver las diferencias aún belicosas arrastradas desde la Unión y sin acudir a la represión armada significó un avance en los procedimientos de gobierno que asentarían unas nuevas formas de afirmación del poder real, respeto a la legalidad y aprovechamiento de los cauces establecidos, institucionales y judiciales que harian del Justicia mayor del reino, por ejemplo, una figura aprovechable y una referencia obligada en muchas causas hasta entonces diluidas e indefinidas entre la justicia real y la local ${ }^{60}$.

50 lbidem.

51 lbidem.

52 Ibidem.

53 GONZÁLEZ ANTÓN, L.: “Jaime II y la afirmación del poder político en Aragón», obra citada.

54 Ibidem.

55 Ibidem.

56 GONZÁLEZ ANTÓN, L.: "Las Cortes aragonesas en el reinado de Jaime Il», obra citada.

57 SARASA, E.: «Las relaciones Iglesia-Estado en Aragón durante la baja Edad Media», en Etat et Eglise dans la genese de /'Etat Moderne, Casa de Velazquez, Madrid 1986, pp. 165-174.

58 SARASA, E.: El Privilegio General de Aragón, obra citada.

59 Ibidem.

60 RODRIGO ESTEVAN, Mª Luz: Documentos para la historia del Justicia de Aragón, Vol. I. Archivo Histórico de la Corona de Aragón, Justicia de Aragón, Zaragoza 1991 (Jaime II, pp. 30-50). 
Comenzando por las Cortes, recién establecidas constitucionalmente después de una primera fase de formación y consolidación, con la incorporación definitiva de algunas representaciones estamentales — como la Iglesia ${ }^{61}$ o las universidades ${ }^{62}$ con presencia permanente, éstas reflejaron la inquietud ante las deficiencias y carencias financieras de la Corona, la quiebra del potencial económico del reino y la pérdida del poder adquisitivo de los particulares.

En efecto, las Cortes del reinado de Jaime II corroboran la inquietud por las carencias financieras de la Corona a través de algunas actuaciones de las asambleas. En primer lugar se intentó fijar algunas rentas destinadas a la Casa Real, tales como los peajes o las rentas de las salinas y de las aljamas ${ }^{63}$; si bien, en el intento susodicho de recomposición de la Hacienda regia, dispersa y descontrolada hasta la fecha por las múltiples alienaciones y dispendios, sobresale como muestra espectacular la fijación regular del impuesto del monedaje, que se empezó a considerar como ordinario y periódico después de que durante el siglo XIII apenas se respetase y normalizase adecuadamente. Dicha imposición tabulada se regularizó en su percepción y recaudación septenal, así como en cuanto a la infraestructura administrativa necesaria para su mejor control ${ }^{64}$; convirtiéndose en una donación asumida y consentida sin apenas resistencia, con la ventaja de ser, además, muy extensiva, a pesar de las exenciones propias de las clases privilegiadas.

Ahora bien, aparte de esta referencia importante sobre el monedaje, algunas asambleas, como la de 1325, elevaron al monarca las quejas de los súbditos por la «presión fiscal» a la que se veían sometidos con tributaciones concretas.

También el empobrecimiento del reino se hizo manifiesto en estas fechas. Se constata, por ejemplo, un quebranto monetario acusado al intentar fijar la moneda jaquesa confirmada por Jaime I y extremar la persecución de la fabricación de falsa moneda ${ }^{65}$, que, al parecer, se difundía con facilidad.

Otros pormenores, como la fijación del derecho de sucesión ${ }^{66}$ (obligado por la frecuencia de los desheredados), la modificación de las condiciones del préstamo usurario (prohibiéndolo a los cristianos y rebajando al máximo el interés) ${ }^{67}$, el impedimento de los nobles para exigir cenas $u$ otros servicios en las villas del reino $0^{68}$, la persecución de los infractores de pesas y medidas ${ }^{69}$, la prohibición de engrosar las arcas privadas con exacciones ilegales o las trabas interpuestas para el establecimiento de monopo-

61 SARASA, E.: «Las relaciones Iglesia-Estado en Aragón durante la Edad Media», obra citada.

62 GONZÁLEZ ANTÓN, L.: «Las Cortes aragonesas en el reinado de Jaime Il», obra citada.

63 Cortes de 1325.

64 ORCÁSTEGUI, C.: «La reglamentación del impuesto del monedaje en Aragón en los siglos XIII-XIV", obra citada.

65 Fueros de 1300 y 1307, en SAVALL, P. y PENEN, S.: Fueros, Observancias y actos de Corte del reino de Aragón, Zaragoza 1866 (reedición facsimilar, Justicia de Aragón, Zaragoza 1992).

66 Cortes de 1307.

67 Cortes de 1301 y 1307.

68 Cortes de 1300.

69 Cortes de 1307. 
lios en determinadas actividades ${ }^{70}$; demuestran todos ellos las dificultades económicas del territorio aragonés en los primeros años del siglo XIV.

Junto a las medidas adoptadas para evitar fraudes, abusos e ilegalidades jurídicoadministrativas 0 comerciales, existen alusiones a malas cosechas ${ }^{71}$, a irregularidades en la comercialización de paños ${ }^{72}$, al levantamiento de la prohibición de exportar mercaderías reservadas ${ }^{73} \mathrm{o}$ al intento de reducir la mendicidad y los asaltos contra la propiedad que se habían convertido en actividad cotidiana y medio de vida frecuen$\mathrm{te}^{74}$. Testimonios todos ellos de una situación generalizada de crisis económica y social que afectaba a todas las clases sociales.

La actividad foral de la época reflejó igualmente la dificil coyuntura atravesada y una realidad que otras fuentes oficiales no recogen con claridad; buscándose indistintamente soluciones socio-políticas o económicas. Entre las primeras se advierten, por ejemplo, las referidas a inmunidades de los eclesiásticos, fijación de fronteras, exigencia de naturaleza aragonesa para el desempeño de cargos y oficios en la administración y gobierno territorial, determinación de las condiciones necesarias para ostentar la representación municipal, reglamentación de las atribucionés y jurisdicciones de los sobrejunteros (encargados de mantener el orden público y de perseguir a los delincuentes), mayor control para evitar los abusos de jueces y notarios en sus salarios y minutas, interdicción de las reuniones de oficios o protección de las personas y bienes de los guerreros descontrolados ${ }^{75}$.

En lo económico, aparte de que algunas medidas socio-políticas repercutieron indirectamente en ello, la resistencia a la admisión de nuevos impuestos, la fijación de la moneda jaquesa o la permisión de la confiscación de los bienes particulares sólo en caso de manifiesta traición al rey, revelan de igual forma el estado de penuria de los contribuyentes y participantes en actividades libres, fuera del marco señorial.

Tras una situación precedente de alteración unionista, vino un tiempo en el que salieron a la superficie las deficiencias de un sistema económico bajo el que se iban a desarrollar diferencias políticas que Jaime II enterró con su esfuerzo pacificador y con el desvío de la atención hacia el Mediterráneo con la empresa de Cerdeña.

Pero las necesidades de la Corona, del reino y de los particulares afloraron de continuo en estos años. Ya en 1291, 1300 y 1301, las Cortes asumieron el carácter recaudatorio de las mismas, coincidiendo con la institucionalización de las asambleas al completar la participación estamental, regular su periodicidad y ampliar la representación ${ }^{76}$.

Hay, pues, un interés económico añadido a la celebración de Cortes desde 1300; a la vez que, por contra, se retrajo la responsabilidad de las asambleas en asuntos

70 Cortes de 1311.

71 Cortes de 1314.

72 Cortes de 1320.

73 Cortes de 1320.

74 Cortes de 1300 y 1301.

75 Fueros de 1300 y 1325 (SAVALL y PENEN, obra citada).

76 GONZÁLEZ ANTÓN, L.: «Las Cortes aragonesas en el reinado de Jaime Il», obra citada. 
político-dinásticos; si bien respecto a la designación de heredero, juramento de fueros $y$ otras actitudes se advierten ciertos cambios precursores ${ }^{77}$.

Durante el reinado de Jaime II, las Cortes intervinieron en muchas cuestiones internas del reino, pero no en la toma de decisiones políticas o militares, de conquista o treguas; ni siquiera en aquellos casos -Agnani o Caltabellota- en los que se truncaron aspiraciones de la monarquía profundamente sentidas ${ }^{78}$.

Esta indecisión y retraimiento pudo deberse, entre otras razones, a que fue en este reinado de Jaime II cuando el Consejo Real empezó a cobrar capacidad de decisión disputada con las Cortes en cuanto a posturas o confrontaciones políticoexpansionistas se refiere, habiendo sido las Cortes de 1283 la última oportunidad del rey para llevar a cabo una consulta institucional sobre un hecho de importancia. Recuérdese la queja aragonesa por la falta de consejo de Pedro el Grande cuando la campaña de Sicilia, por las repercusiones negativas que los representantes del reino consideraban que podía tener la empresa; postura muy distinta a la que dichos representantes adoptaron después, con Jaime II, con motivo de la ocupación de Cerdeña ${ }^{79}$.

Las Cortes de 1325, con la agudización de la crisis estructural del «reino cabeza de la Corona», fueron especialmente significativas ${ }^{80}$. En primer lugar hay que señalar que Aragón no había visto reunidas sus Cortes desde 1320, mientras que Cataluña - a pesar del interés centrado por entonces en la empresa sarda- había celebrado Cortes en 1321 y en Gerona ${ }^{81}$, preparándose ya la intervención en Cerdeña para la que el infante - futuro Alfonso IV de Aragón-solicitaría de las comunidades ibéricas aragonesas de Calatayud, Teruel y Daroca la correspondiente ayuda ${ }^{82}$.

Pero sucesivas prórrogas en la pretensión de convocar a los aragoneses a Cortes produjeron en este intervalo temporal, abierto desde $1320^{83}-$ y celebrándose las de Barcelona en 1323-, una disidencia interna que precedió a la convocatoria inicial de septiembre de $1324^{84}$, que no sería la definitiva ${ }^{85}$.

77 GONZÁLEZ ANTÓN, L.: «Jaime II y la afirmación del poder monárquico en Aragón», obra citada.

78 Por el tratado de Anagni —firmado en 1295 por Jaime II, Felipe IV de Francia, Carlos II de Nápoles y el papa Bonifacio VIII - se trató de superar la dificultades internacionales surgidas con la conquista aragonesa de Sicilia en 1282 por Pedro lil el Grande. De manera que se levantaron las sentencias contra Aragón de excomunión y entredicho a cambio de que Jaime II retornase Sicilia al papa y Mallorca a su rey Jaime II.

En cuanto a la paz de Caltabellota firmada en 1302 por Carlos II de Anjou y Federico II de Sicilia, aseguraba la independencia sícula, aunque Sicilia quedaría regida por príncipes salidos de la casa de Aragón y constituiría una base importante para el comercio catalán en el Mediterráneo.

79 Ver nota 12.

80 Archivo de la Corona de Aragón (A.C.A.), Registro de Cancillería 308, fols. 250v. a 253v.; y Real Academia de la Historia, Manuscrito A-2 (Colección Salazar), fols. 255-264.

81 Cortes de Cataluña (Real Academia de la Historia), tomo I, pp. 258-272.

82. ZURITA, Anales de la Corona de Aragón, libro VI, capítulo 39.

83 A.C.A. Registro de Cancillería 308, fols. 243-245v.

84 Ibidem, fols. 247-248v.

85 Ibidem, fols. $249-250$. 
Así fue. Una nueva prórroga y la reunión del Consejo Real amplio en Lérida ${ }^{86}$ - para tratar de la oportunidad de recuperar el reino de Mallorca tras la muerte sin heredero del rey Sancho- llevó finalmente al comienzo de las Cortes en Zaragoza, a donde había acudido el rey el 12 de septiembre de aquel año $1325^{87}$; siendo el motivo principal de la convocatoria la resolución pendiente desde 1320 de las reclamaciones sobre el incumplimiento del Privilegio General; reclamaciones a las que el rey dio cumplida respuesta en forma de unas constituciones en veintidós capítulos y que tuvieron amplia repercusión ${ }^{88}$.

Las Cortes de 1325, últimas del reinado, atendieron en sus ordenaciones a las numerosas protestas elevadas a la asamblea sobre política impositiva ${ }^{89}$, que se había ido introduciendo y estrechando a tenor de lo que se podía entender como déficit manifiesto de las finanzas públicas, especialmente por el descontrol de los recursos de la monarquía en el reino ${ }^{90}$ y en lo que afectaba a Aragón, la decadencia de las aljamas $^{91}$ o la deuda de particulares acumulada, por entonces, y manifiesta reiteradamente en los primeros años de Pedro el Ceremonioso ${ }^{92}$.

Acaso las reclamaciones de estas Cortes ante el rey no eran sino el colofón de una espiral ascendente de avance de las dificultades económicas del reino y de precaución del monarca para frenar el déficit recaudatorio en el mismo. Dichas dificultades habían aparecido ya en 1301 y 1307, cuando se rebajó el límite superior del interés usurario ${ }^{93}$, y prosiguieron en 1311 , cuando se trató de evitar el fraude en la compraventa de paños ${ }^{94}$. así como también en 1320 , al suspender la interdicción de la exportación de ciertas mercancías protegidas ${ }^{95}$.

Junto a estas medidas de urgencia, desde comienzos de siglo también se intentó atajar la proliferación del hurto y la mendicidad como medios de subsistencia habituales ${ }^{96}$. y no tanto como mera marginalidad o indigencia, así como los abusos de los

86 Al que acudieron algunos clérigos y ricoshombres, sólo dos caballeros y dos ciudades aragonesas, frente a una mayor presencia catalana (ZURITA: Anales, libro VI, cap. 57).

87 A.C.A. Registro de Cancillería, 308, fols. 253-253v.

88 Ibidem, fols. 250-253v; y Registro 227, fols. 250-253.

89 SAVALL y PENEN: Fueros, observancias y actos de Corte del reino de Aragón, obra citada, artículos 4, 9, 10, 15, 18 y 25 (pp. 17, 18, 19, 20).

90 ORCÁSTEGUI, C. y SARASA, E.: «El libro-registro de Miguel Royo, merino de Zaragoza en 1301: una fuente para el estudio de la sociedad y economía zaragozanas a comienzos del XIV", en Aragón en la Edad Media IV, Zaragoza 1981, pp. 87-155; y «Miguel Palacín, merino de Zaragoza en el siglo XIV: 1339-1342", Ibidem I, 1977, pp. 51-131.

91 MOTIS, M.A.: «Inicio del declive (judio) en Aragón durante el siglo XIV: Jaime II» (Historia de Aragón 6, pp. 150-154).

92 En los primeros años del reinado de Pedro IV existen muchas peticiones de particulares sobre moratoria de deudas.

93 SAVALL y PENEN: Fueros...I, p. 204 y II, p. 115.

94 Ibidem, I, p. 221.

95 A.C.A.: Registro de Cancillería 247, fol. 174.

96 SAVALL y PENEN, Fueros..., I, pp. 341 y 240. 
poderosos en la exigencia de tributaciones o servicios especiales a las poblaciones del reino ${ }^{97}$.

La importancia de las Cortes de 1325 como punto de referencia para rastrear el proceso de recesión y dificultades económicas inherentes en Aragón, es notoria; teniendo en cuenta, además, el complicado momento que atravesaba la política dinástica y los intereses catalanes en particular, con la apertura del horizonte sardo y la posibilidad de reversión mallorquina a la Corona.

Las dificultades surgidas para controlar eficazmente la administración de los recursos derivados de los derechos y exacciones reales se delatan en los registros de los administradores de dichas rentas ${ }^{98}$, lo cual coincide con la profusión de quejas sobre la intención del soberano de introducir contribuciones desconocidas en el país, o regular decididamente la percepción de algunas que se habían iniciado como excepcionales para transformarse en ordinarias, dada su extensión por todo el territorio y por afectar a buena parte de la población, como sucedió con el monedaje ${ }^{99}$.

A propósito del monedaje, Jaime II había concedido en 1302 la exención del mismo a todas las aljamas de los judíos del reino a petición de los afectados que le venían manifestando su penuria económica ${ }^{100}$; el mismo año en el que el rey concedió asimismo a la Orden del Temple la percepción de la mitad de lo correspondiente a su persona por este concepto en lugares de señorío militar ${ }^{101}$, encargándose un oficial regio y un representante de la milicia templaria de la recaudación; cesión que haría el rey extensible a la orden de San Juan de Jerusalen en las mismas condiciones ${ }^{102}$.

Aunque lo más destacado fue la normativa definitiva que este monarca estableció para la recaudación del monedaje en cuestión, quedando ajustado a la realidad del momento el procedimiento a seguir y las personas a las que les afectaba ${ }^{103}$ : todas de condición o servicio, cristianos y moros, que poseyeran bienes patrimoniales o raices superiores a una estimación de setenta sueldos jaqueses, contribuyedo con un maravedí (siete sueldos de moneda jaquesa) cada siete años; estando exentos los ricohombres, caballeros, infanzones y clérigos en general, salvo que estos dos últimos se dedicasen a negocios o actividades «impropias» de su condición ${ }^{104}$.

Se trataba de ajustar la normativa recaudatoria a la realidad socioeconómica en el nacimiento de una nueva mentalidad fiscal, buscando aproximar la realidad social a la tributaria y aumentar los recursos de la monarquía. Pero junto a las prácticas fiscales reguladoras y normalizadoras del reinado de Jaime II, que tenían como finalidad el

97 Por ejemplo las cenas (SAVALL y PENEN: I, 248).

98 Registros de los Bailes Generales de Aragón: A.C.A., Real Patrimonio, núm. 1688 (año 1310).

99 ORCÁSTEGUI, C.: "La reglamentación del impuesto del monedaje en Aragón en los siglos XIII-XIV», obra citada.

100 A.C.A. Registro de Cancillería 304, fol. I y IV.

101 Ibidem.

102 Ibidem.

103 ORCÁSTEGUI, C.: «La reglamentación...», pp. 118-121. Capitoles de cómo se deve collir el moravedí en Aragón (Biblioteca de El Escorial, manuscrito J-IIl-21, fols. 145-149).

104 Ibidem. 
evitar el descontrol financiero y el obtener una recaudación mayor en esos años de dificultades, existieron otros indicios que abundan sobre la penuria económica de los contribuyentes ordinarios u ocasionales y la escasa disponibilidad de medios y recursos que heredaron sus sucesores. Dichos indicios son, por ejemplo, la precaria contribución económica de los aragoneses a la empresa de Cerdeña o el descenso en la concesión oficial de mercados y ferias después del auge del siglo XIII ${ }^{105}$.

Respecto a la participación contributiva de Aragón a la política expansionista mediterránea, ya desde el comienzo de la ocupación de Cerdeña en 1323, la aportación humana de los aragoneses fue notable en proporción con la menguada contribución económica; viendo en dicha empresa una posibilidad de promoción social que se había desaprovechado, en cambio, cuando la de Sicilia ${ }^{106}$. Lo cual indica, por otra parte, que la nobleza estaba buscando, con este soberano pacificador y diplomático, una ratificación de su preponderancia politico-social en el reino; preponderancia puesta en duda desde finales del siglo XIII por las crisis internas de su clase y la presión del resto social aragonés y del propio rey.

En la preparación previa de la campaña sarda, la disposición real por la que la Iglesia aragonesa debía colaborar a través de la entrega de las décimas durante tres años, apenas fue cumplida ${ }^{107}$. Pero, después, ya en plena urgencia de la recaudación de recursos, lo entregado no correspondió a lo inicialmente calculado y prometido ${ }^{108}$; limitación que también se dio en la participación personal de caballeros con sus mesnadas; dedicándose lo recaudado en Aragón, en buena parte, a la reposición de los préstamos conseguidos por el monarca en Perpignan y Montpellier para la intervención en Cerdeña ${ }^{109}$.

En cuanto al ritmo de creación y autorización de mercados y ferias, que en el siglo XIII había sido constante, se frenó desde comienzos del XIV; conociéndose únicamente, en los años comprendidos, la concesión en 1301 de dos ferias a Tarazona ${ }^{110}$ (para julio y septiembre), otra segunda feria a Monzón en 1311 en septiembre ${ }^{111}$ y la concedida a Huesca en 1326 para el mes de noviembre ${ }^{112}$.

Tras las dificultades derivadas de la recesión económica, la crisis estructural y la división social de finales del siglo XIII y pese a los esfuerzos de Jaime II por superar las causas que habían provocado las mismas (reforzando las instituciones, reconstru-

105 ORCÁSTEGUI, C.: «Ferias y mercados en la Edad Media. Fuentes para su estudio y metodología", en $V$ Jornadas de Metodología de la Investigación Científica sobre Fuentes Aragonesas, Instituto de Ciencias de la Educación y Diputación General de Aragón, Zaragoza 1990, pp. 21-45.

106 SARASA, E.: El Privilegio General de Aragón, obra citada; y obra citada en la nota 12.

107 SALAVERT, V.: Cerdeña y la expansión mediterránea de la Corona de Aragón, 1297-1314, Madrid 1956, vol. II, docs. 48 y 49.

108 De unos 707.500 sueldos jaqueses prometidos no se llegaría ni a la mitad (ORCÁSTEGUI, C.: obra citada en la nota 12 ).

109 Ibidem.

110 A.C.A. Registro de Cancillería 199, fol. 109.

111 Ibidem 16, fol. 202.

112 LALIENA, C.: Documentos municipales de huesca, 1100-1350, Huesca 1988, doc. 122. 
yendo el patrimonio, reordenando la fiscalidad y la administración, y buscando la implicación social en sus proyectos), se puede fijar la atención, finalmente, en cuatro muestras efectivas de la situación latente en este primer tercio del siglo XIV que volvería a explotar con Pedro el Ceremonioso y el rebrote de la Unión: la primera se refiere a la administración de las finanzas reales ${ }^{113}$, la segunda a la situación de las economías señoriales ${ }^{114}$, la tercera a la penuria de particulares o colectivos locales cargados de deudas y con apuros para saldarlas ${ }^{115}$, y la cuatra relacionada con la producción cerealista y su descenso en cantidad y calidad ${ }^{116}$.

La quiebra de las finanzas reales disponibles en Aragón obligó posteriormente a Alfonso IV (1327-1334) a revisar el cómputo y relación de las caballerías distribuidas por el reino'17, dado el enorme esfuerzo que suponía cumplir con la asignación que correspondía por dicho concepto a ricoshombres y caballeros; revisión que ya Jaime I habia intentado hacer en $1271^{118}$. Las protestas de localidades cuyas rentas disfrutaban los nobles sin justificación y la necesidad de regularizar el sistema obligaron a la intervención del rey en el asunto.

En cuanto a las difilcultades señoriales, ejemplos como el de la Orden de Calatrava en Alcañiz son representativos de una situación generalizada, con un crecimiento de la deuda externa, inusual hasta entonces, y un descenso notable de la fiscalidad real correspondiente a dicha Orden ${ }^{119}$ : situación que se dio también en otros señorios religioso-militares que rivalizaron con la nobleza laica y la propia monarquía por el reparto de los beneficios de la tierra ${ }^{120}$, así como en los dominios monásticos aragoneses. En el de San Juan de la Peña en concreto hubo disputas de rentas y propiedades con los nobles, enfrentamientos con poblaciones sometidas a vasallaje por la negativa al pago de tributos y prestaciones personales o controversias provocadas en la venta y circulación de la sal' ${ }^{121}$.

Sobre los apuros de los particulares en poblaciones de realengo y, por lo tanto, no sometidas a la presión señorial, a partir del reinado de Jaime It, son significativas las

113 Las dificultades en la percepción y administración de las rentas reales en Aragón se manifiesta en los registros de merinos ya mencionados y publicados, nota 90; así como en el del baile de 1310 , nota 98 .

114 Las dificultades económicas señoriales se reflejan, entre otros aspectos, en la exigencia indebida de tributos y que las Cortes trataron de impedir desde 1300.

115 La documenmtación municipal de estos años recoge las súplicas de los concejos sobre demoras de contribuciones aún no satisfechas a causa de las dificultades para saldarlas.

116 Cortes de 1314, A.C.A. Registros de Cancillería 308, fols. 233v. y 234.

117 Biblioteca Nacional de Madrid, Manuscrito 746, fols. 239v. a 244.

118 A. CANELLAS, Doce documentos fiscales aragoneses del siglo XIII de la alacena de Zurita, Institución Fernando el Católico, Zaragoza 1983, pags, 8-57.

119 LALIENA, C.: Sistema social, estructura agraria y organización del poder en el bajo Aragón en la Edad Media: siglos XII-XV, I.E.T., Teruel 1975, p. 142.

120 SAINZ DE LA MAZA, R.: La Orden Militar de Santiago en Aragón, Zaragoza 1975, doc. 136.

121 LAPEÑA PAUL, A.I.: El monaterio de San Juan de la Peña en la Edad Media, Zaragoza 1989, pp. 230-248. 
continuas solicitudes y concesiones, en su caso, de moratorias de deudas en ciudades y villas aragonesas: Zaragoza, Sariñena, Huesca, etc. ${ }^{122}$.

Y en lo referido a las cosechas, en las Cortes de 1314 ya se había mencionado la penuria: "quod in toto Aragonum tante urgent victualium penuria et nimia caristia que propter sterilitatem temporis evenerunt quod in eo minime convenit tali tempore generalem curiam celebrare ${ }^{123}$.

A pesar de lo cual, en el reinado de Jaime II en Aragón, las Cortes y el Justicia se fortalecieron, ampliándose competencias y aumentando sus servicios ${ }^{124}$. Los cargos públicos (bailes, merinos y sobrejunteros) se institucionalizaron en sus funciones ${ }^{125}$. El desorden social se contuvo y recondujo hacia la estabilidad superadora de los dos grandes retos del momento: la supresión de la Orden del Temple ${ }^{126}$ y la reanudación de la expansión mediterránea ${ }^{127}$. Y la reconstrucción económica, fiscal y patrimonial se intentó y logró en parte ${ }^{128}$. Aunque, en definitiva, con Pedro el Ceremonioso se vio que la superación de las deficiencias y contradicciones, de las carencias y desequilibrios de los aragoneses con Jaime II fue algo transitorio a pesar de los muchos logros temporales y permanenetes del monarca llamado también el Justo ${ }^{129}$, de la atención prestada a los subditos de su reino continental ${ }^{130}$ y de la trayectoria pacificadora $y$ recomponedora de su gobierno.

La presente es por tanto una mera apuesta por la necesidad de profundizar en el estudio y análisis de lo que supuso el reinado de Jaime II en Aragón dentro de la trayectoria de la monarquía y de la experiencia aragonesa medieval. Porque, de lo antedicho, puede concluirse que el mencionado reinado se desenvolvió en una cuarentena de años aproximadamente que representaron para el reino el final de una época y el comienzo de otra en la que nuevos retos, dificultades y desavenencias provocaron a la larga la vuelta a la guerra civil (la Unión de nuevo en 1347-48), la pérdida de peso político en el conjunto de la Corona (a partir de Pedro IV) y la quiebra del orden social conseguido por Jaime II con la sobreimposición de la alta nobleza, el predominio señorial y la escasa efectividad de los demás sectores sociales (nobleza media, burgueses y gentes de oficio y mercaderes, minorias y funcionariado) que con este monarca habían empezado a despuntar para regresar a la travesía del desierto impuesta por la recuperación del poder nobiliario.

122 A.C.A. Cartas Reales de Pedro el Ceremonioso, núms. 571, 627, 629, 637, 655, 660, 665, 682 y 695 (del comienzo del reinado).

123 A.C.A. Registro de Cancillería 308, fols. 233v. y 234.

124 Ver nota 60 respecto al Justicia.

125 Ver nota 11.

126 Ver nota 32.

127 Ver nota 12.

128 Ver nota 11.

129 SARASA, E.: «El enfrentamiento de Pedro el Ceremonioso con la aristocracia aragonesa: la guerra con la Unión y sus consecuencias", en Pere el Cerimoniós i la seva època, Anuario de Estudios Medievales, Annex 24, Barcelona 1989, pp. 35-45.

130 Ver nota 11. 